\title{
KARAKTER AGRONOMI PADI RATUN (ORIZA SATIVA. L) VARIETAS LOKAL PASANG SURUT TANJUNG JABUNG TIMUR
}

\author{
Mapegau $^{1 *}$, Asrizal Paiman ${ }^{1)}$, dan Marlina ${ }^{2)}$ \\ 1) Jurusan Agroekoteknologi FakultasPertanianUniversitas Jambi \\ Jl. Raya Jambi - Ma. Bulian KM.15 Mendalo Darat, 36136 \\ Email : gau_agrotek@yahoo.com (*Penulis untuk korespondensi) \\ 2) Jurusan Proteksi Tanaman FakultasPertanianUniversitasSyiah Kuala
}

\begin{abstract}
ABSTRAK
Penelitian lapangan yang bertujuan untuk mempelajari karakter agronomi ratun dari beberapa varietas padi lokal pasang surut Tanjung Jabung Timur(Tanjabtim) telah dilaksanakan di lahan petani Desa Lambur Luar Kecamatan Sabak Timur, Kabupaten Tanjabtim. Penelitian ini menggunakan rancangan acak kelompok (RAK) tiga ulangan. Lima varietas padi lokal pasang surut berupa tanaman induk yang digunakan sebagai perlakuan adalah: Temon, Dawi, Sere, Minang, dan Pulo. Bibit padi yang telah berumur 3 minggu dipersemaian ditanam pada petakan berukuran $3 \times 2 \mathrm{~m}$ dengan jarak tanam $30 \times 25$ $\mathrm{cm}$. Tinggi pemotongan rumpun tanaman induk $20 \mathrm{~cm}$ dari permukaan tanah.

Hasil penelitian menunjukkan bahwa ratun tertinggi diperoleh dari tanaman induk varietas Pulo $(101,07 \mathrm{~cm})$ dan varietas Minang $(87,60 \mathrm{~cm})$. Ratun dengan tinggi terendah diperoleh dari tanaman induk varietas Sere $(51,23 \mathrm{~cm})$. Jumlah anakan ratun tertinggi diperoleh pada tanaman induk Varietas Sere yaitu 58,04 batang/rumpun, tetapi yang produktif 27,28 batang/rumpun atau $47 \%$. Tanaman induk Variets Pulo menghasilkan ratun dengan jumlah anakan 40,87 batang/rumpun dan yang produktif sebanyak 37,98 batang/rumpun atau 92,93\%, sedangkan tanaman induk Varietas Minang menghasilkan anakan ratun sebanyak 45,33 batang/rumpun dan yang produktif 40,22 batang/rumpun atau $88,73 \%$. Malai terpanjang diperoleh pada ratun dari varietas Minang dan Pulo masingmasing $22,61 \mathrm{~cm}$ dan $22,20 \mathrm{~cm}$. Sedangkan malai terpendek diperoleh pada ratun dari tanaman induk varietas Sere $(15,58 \mathrm{~cm})$. Jumlah gabah per malai tertinggi diperoleh pada varietas Pulo (161,45 butir) dan yang berisi sebanyak 92,12 butir (57,06\%). Varietas Minang menghasilkan gabah per malai 154,13 butir dan yang berisi $106,13(68,86 \%)$, varietas Sere 100,54 butir per malai yang berisi 14,87 butir (14,79\%). Jumlah gabah per malai varietas Dawi adalah sebanyak 107,68 butirdan yang berisi 77,68 butir (72,14\%), varietas Temon 105,10 butir per malai dan yang berisi 50,10 butir (47,67\%). Ratun dari tanaman induk Varietas Minang dan Pulo lebih mampu mempertahankan kehijauan daun dan pangkal batang dan bentuk sudut daun yang lebih tegak.
\end{abstract}

Kata kunci: Ratun, karakter agronomi, padi pasang surut.

\section{PENDAHULUAN}

Setiap tahun Indonesia masih mengimpor beras sebesar 2 juta ton. Jumlah ini diperkirakan masih terus mengalami peningkatan sejalan dengan tingkat pertumbuhan penduduk yang masih relatif tinggi yaitu $1,4 \%$ per tahun. Dengan laju pertumbuhan penduduk yang relatif besar itu dan laju konsumsi beras nasional sebesar 1.34\% per tahun, 
maka produktivitas padi nasional seharusnya minimal 6.0 t/ha. Akan tetapi nampaknya hal ini sulit dicapai hanya dengan mengandalkan produksi padi sawah beririgasi dan tadah hujan. Oleh karena itu peningkatan produktivitas dan intensitas panen padi pasang surut yang tersebar luas di Indonesia, termasuk di Kabupaten Tanjung Jabung Timur (Tanjab Tim) sangat prospektif dalam memberikan tambahan produksi.

Alternatif yang dapat dilakukan adalah dengan memelihara ratun, yakni tunas tanaman padi yang tumbuh dari tunggul yang telah dipanen, sehingga dapat memberikan tambahan produksi (Flinn \& Mercado 1988; Islam et al. 2008). Penngembangan budidaya ratun telah diperaktikkan dalam skala komersial di beberapa negara seperti USA, China, India, Jepang, Thailand dan Filipina. Ada beberapa keuntungan dalam budidaya ratun antara lain, umur panen relatif lebih pendek, kebutuhan air lebih sedikit, biaya produksi lebih rendah karena hemat dalam pengolahan tanah dan penggunaan bibit serta hemat dalam perawatan.

Tidak semua varietas mampu menghasilkan ratun yang dapat tumbuh dan berproduksi dengan baik, tergantung varietasnya. Dari hasil penelitian Nadal dan Caragal (1979) diketahui bahwa di India ratun dari varietas Intan mampu berproduksi bahkan melebihi produksi tanaman induknya, yaitu $140 \%$ dari panen utama. Secara genetik dilaporkan bahwa padi-padi lokal memiliki sifat ratun dan anakan sekunder. Varietas seperti ini banyak ditemukan di Asia terutama di habitat lahan rawa. Di daerah pasang surut Kabupaten Tanjung Jabung Timur (TanjabTim) ada beberapa varietas padi lokal yang sudah biasa dibudidayakan oleh petani.

Ratun dari tanaman induk umumnya dibiarkan tumbuh secara alami tanpa masukan teknologi sehingga produksinya belum optimal. Untuk itu diperlukan upaya untuk mempelajari dan mendapatkan informasi dalam rangka meningkatkan potensi ratun secara optimal dari tanaman induk yang ada.

\section{BAHAN DAN METODE}

\section{Bahan dan Rancangan Percobaan}

Bahan yang digunakan dalam penelitian ini adalah benih padi varietas lokal yaitu, Temon, Dawi, Sere, Minang, dan Pulo. Untuk menghindari adanya srangan jamur pada tumnggul tanaman induk yang telah dipangkas digunakan fungisida Dithane-45. 
Penelitian dilaksanakan dengan menggunakan rancangan Acak Kelompok (RAK) tiga ulangan. Lima varietas padi lokal pasang surut sebagai perlakuan yaitu: Temon, Dawi, Sere, Minang, dan Pulo.

\section{Pelaksanaan Penelitian}

Penelitian ini dilaksanakan di lahan petani Desa Lambur Luar Kecamatan Sabak Timur, Kabupaten Tanjung Jabung Timur (Tanjab Tim). Pengolahan tanah seperti pencangkulan atau penggaruan juga tidak dilakukan. Petak percobaan dibuat dengan ukuran 3 x 2 m, jarak antar petakan dibatasi oleh parit kecil berukuran lebar $20 \mathrm{~cm}$ dengan kedalaman $15 \mathrm{~cm}$.

Benih padi terlebih dahulu direndam selama 24 jam, kemudian dikering anginkan selama 5 jam selanjutnya dilakukan penyemaian. Bibit yang telah berumur 3 minggu dipersemaian kemudian ditanam pada kondisi lahan macak-macak dengan jarak tanam 30 x $25 \mathrm{~cm}$. Tidak digunakan pupuk NPK sebagai pupuk dasar karena disesuaikan dengan kebiasaan petani. Panen tanaman induk dilakukan dengan cara pemotongan atau memangkas rumpun padi pada ketinggian $20 \mathrm{~cm}$ dari permukaan tanah. Satu hari setelah pemangkasan (panen ) tanaman induk dilakukan penyemprotan dengan fungisida Dithane M-45 terhadap rumpun/tunggul padi sisa pemotongan untuk menghindari infeksi oleh jamur.

\section{Peubah yang diamati}

Pengamatan dilakukan terhadap pertumbuhan, hasil dan komponen hasil ratun yang tumbuh dari tanaman induk. Pengamatan terhadap pertumbuhan meliputi: tinggi tanaman, jumlah anakan, jumlah anakan produktif, dan umur berbunga. Peubah hasil dan komponen hasil yang diamati meliputi: bobt gabah kering per rumpun, panjang malai, jumlah gabah per malai, dan jumlah gabah berisi per malai. Pengamatan secara visual meliputi: bentuk kanopi (sudut daun), kondisi daun (kehijauan dan jangka hidup daun), dan kehijauan batang.

\section{Analisis data}

Data yang terkumpul dari hasil pengamatan terhadap ratun baik pertumbuhan maupun hasil dan komponen hasil dianalisis secara statistik dengan metode sidik ragam dan dilanjutkan dengan uji BNT pada taraf $\alpha 5 \%$. 


\section{HASIL DAN PEMBAHASAN}

\section{Pengamatan visual}

Produksi tanaman padi umumnya dapat ditingkatkan dengan memaksimalkan penyerapan cahaya dan meningkatkan penggunaan cahaya. Hal ini dapat ditentukan antara lain oleh : (a) bentuk kanopi (sudut daun), (b) kondisi daun (kehijauan dan jangka hidup daun), dan (c) kehijauan batang. Dari 5 varietas tanaman induk yang diuji pada penelitian ini, menunjukkan bahwa ratun dari tanaman induk varietas Minang Dan Pulo relatif mampu mempertahankan kehijauan daun dan pangkal batang. Hal ini akan meningkatkan laju fotosintesis tanaman dan produksi biomassa (Long et al. 2006). Dalam hubungannya dengan bentuk kanopi, sudut daun dari ratun tanaman induk varietas Minang dan Pulo lebih tegak, sedangkan sudut daun ratun dari tanaman induk varietas Temon dan Dawi relatif tegak. Ratun dari tanaman induk varietas Sere tampak lebih datar. Padi dengan sudut daun lebih tegak akan memiliki potensi produksi lebih tinggi dibandingkan yang bersudut daun datar (Long et al. 2006). Selain itu saat cahaya matahari penuh, fotosintesis pada bagian atas kanopi yang tegak akan terjadi secara langsung dan cepat, sehingga jumlah pati yang terbentuk tinggi dan dapat mengakibatkan terjadinya penimbunan butir pati di kloroplas, serta di batang dan kortek untuk pertumbuhan berikutnya (Murchie et al. 2002). Varietas dengan karakter seperti ini berpotensi menghasilkan ratun dengan pertumbuhan dan hasil yang lebih baik. Hal ini akan lebih jelas terlihat dalam uraian pertumbuhan, hasil dan komponen hasil berikutnya.

\section{Pertumbuhan}

Hasil penelitian menunjukkan bahwa ratun tertinggi dihasilkan dari tanaman induk varietas Minang dan Pulo kemudian diikuti oleh ratun dari tanaman induk Varietas Temon dan Dawi, sedangkan ratun terendah diperoleh dari tanaman induk Varietas Sere. Tidak ada perbedaan antara tinggi ratun dari tanaman induk varietas Minang dengan ratun dari tanan induk Varietas Pulo. Tetapi ratun dari kedua varietas tanaman induk ini secara nayata lebih tinggi dari ratun varietas tanaman induk lainnya (Tabel 1). Jumlah anakan ratun tertinggi dihasilkan dari tanaman induk Varietas Sere yaitu 58,04 batang/rumpun tetapi yang produktif hanya 27,28 batang/rumpun atau $47 \%$. 
Tabel 1. Karakter pertumbuhan ratun dari beberapa varietas tanaman induk

\begin{tabular}{ccccc}
\hline Varietas & $\begin{array}{c}\text { Tinggi } \\
\text { tanaman } \\
(\mathrm{cm})\end{array}$ & $\begin{array}{c}\text { Jumlah anakan } \\
\text { ratun(batang/rumpun) }\end{array}$ & $\begin{array}{c}\text { Jumlah anakan ratun } \\
\text { produktif(batang/rumpun) }\end{array}$ & $\begin{array}{c}\text { Umur } \\
\text { berbunga } \\
\left.(\text { HST })^{*}\right)\end{array}$ \\
\hline Temon & $72,17 \mathrm{a}$ & $32,20 \mathrm{a}$ & $21,69 \mathrm{a}$ & $65,73 \mathrm{~b}$ \\
Dawi & $71,31 \mathrm{a}$ & $33,24 \mathrm{a}$ & $23,50 \mathrm{a}$ & $59,61 \mathrm{a}$ \\
Sere & $51,23 \mathrm{~b}$ & $58,04 \mathrm{~b}$ & $27,28 \mathrm{a}$ & $101,01 \mathrm{c}$ \\
Minang & $97,60 \mathrm{c}$ & $45,33 \mathrm{c}$ & $40,22 \mathrm{~b}$ & $53,47 \mathrm{a}$ \\
\hline Pulo & $101,67 \mathrm{c}$ & $40,87 \mathrm{c}$ & $37,98 \mathrm{~b}$ & $53,56 \mathrm{a}$
\end{tabular}

Angka-angka yang diikti oleh huruf yang sama tidak berbeda nyata pada taraf 5\% menurut uji BNT. *) Hari SetelahTanam

Jumlah anakan ratun yang dihasilkan dari tanaman induk Varietas Minang dan tanaman induk Varietas Pulo secara nyata lebih rendah dari jumlah anakan ratun yang dihasilkan dari tanaman induk Varietas Sere. Ratun dari tanaman induk Varietas Minang menghasilkan anakan sebanyak 45,33 batang/rumpun dan yang produktif 40,22 batang/rumpun atau 88,73\%. Ratun dari tanaman induk Varietas Pulo menghasilkan anakan sebanyak 40,83 batang/rumpun dan yang produktif 37,98 batang/rumpun atau 92,93\%. Diduga hal ini berhubungan cadangan makanan yang tersimpan pada tunggul sisa panen tanaman induk Varietas Minang dan tanaman induk Varietas Pulo. Lebih lanjut (Vergara et al. 1988; Chauhan et al. 1989; Gardner et al. 1991) mengemukakan bahwa penyimpanan hasil fotosintesis ke bagian akar dan batang sangat diperlukan, agar batang tanaman padi yang telah dipanen (tunggul) tetap berwarna hijau. Dengan demikan asimilat yang dihasilkan dapat dimanfaatkan untuk pertumbuhan tunas ratun.

\section{Komponen hasil dan hasil}

Hasil penelitian menunjukkan bahwa malai terpanjang dihasilkan oleh ratun dari tanaman induk Varietas Minang dan Pulo. Sedangkan malai terpendek diperoleh pada ratun dari tanaman induk Varietas Sere. Tidak ada perbedaan antara panjang malai dari tanaman induk varietas Minang dengan panjang malai dari tanan induk Varietas Pulo. Tetapi panjang malai dari kedua varietas tanaman induk ini secara nayata lebih panjang dari ratun varietas tanaman induk lainnya. Jumlah gabah/malai terbanyak dihasilkan oleh ratun dari tanaman induk varietas Minang dan Pulo masing-masing 154,13 butir/malai dan 161,45 butir/malai (Tabel 2). 
Tabel 2. Komponen hasil dan hasil ratun dari beberapa varietas tanaman induk

\begin{tabular}{ccccc}
\hline Varietas & $\begin{array}{c}\text { Panjang } \\
\text { malai }(\mathrm{cm})\end{array}$ & $\begin{array}{c}\text { Jumlah } \\
\text { gabah/malai (butir) }\end{array}$ & $\begin{array}{c}\text { Jumlah gabah } \\
\text { isi/malai (butir) }\end{array}$ & $\begin{array}{c}\text { Bobot gabah } \\
\text { kering/rumpun }(\mathrm{g})\end{array}$ \\
\hline Temon & $20,23 \mathrm{~b}$ & $105,10 \mathrm{a}$ & $50,10 \mathrm{~b}$ & $32,72 \mathrm{c}$ \\
Dawi & $20,73 \mathrm{~b}$ & $107,68 \mathrm{a}$ & $77,68 \mathrm{c}$ & $42,80 \mathrm{c}$ \\
Sere & $15,56 \mathrm{a}$ & $100,54 \mathrm{a}$ & $14,87 \mathrm{a}$ & $24,57 \mathrm{a}$ \\
Minang & $22,61 \mathrm{c}$ & $154,13 \mathrm{~b}$ & $146,13 \mathrm{~d}$ & $56,17 \mathrm{~b}$ \\
\hline Pulo & $22,20 \mathrm{c}$ & $161,45 \mathrm{c}$ & $132,12 \mathrm{~d}$ & $54,40 \mathrm{~b}$
\end{tabular}

Angka-angka yang diikuti oleh huruf yang sama tidak berbeda pada taraf 5\% menurut uji BNT

Jumlah gabah berisi/malai yang dihasilkan dari ratun tanaman induk Varietas Minang dan Pulo nyata lebih banyak dari jumlah gabah berisi/malai yang dihasilkan dari ratun tanaman induk Varietas Sere, Dawi, dan Temon. Dari hasil penelitian ini didapatkan bahwa ratun dari tanaman induk Varietas Minang dan ratun tanaman induk varietas Pulo menghasilkan jumlah gabah berisi terbanyak, masing-masing sebanyak 146,13 butir/malai atau $94,81 \%$ dari jumlah gabah/malai dan 132,12 butir/malai atau 81,83\%, diikuti kemudian oleh ratun dari tanaman induk varietas Dawi sebanyak 77,68 butir/malai atau $72,14 \%$. Bobot gabah kering/rumpun tertinggi juga diperoleh pada ratun dari tanaman induk Varietas Minang dan ratun tanaman induk Varietas Pulo, berturut-turut sebesar $56,17 \mathrm{~g}$ dan 54,40 g. Diikuti kemudian ratun dari tanaman induk Varietas Dawi.

\section{KESIMPULAN}

Berdasarkan hasil penelitian yang telah diuraiakn di atas, dapat diambil kesimpulan bahwa ratun dengan karakter sudut daun lebih tegak, mampu mepertahankan kehijauan daun dan kehijauan pangkal batang, dan lebih tinggi, dapat tumbuh dan berproduksi dengan baik dan menghasilkan anakan ratun produktif dalam jumlah yang lebih banyak. Pada penelitian ini karakter-karakter tersebut dihasilkan dari tanaman induk Varietas Minang, Pulo, diikuti oleh tanaman induk Varietas Dawi dan tanaman induk Varietas Temon.

\section{DAFTAR PUSTAKA}

Chauchan J.S, B.S. Vergara dan S.S. Lopez. 1985. Rice Ratooning. IRRI Research Paper Series. Number 102 . February 1985. IRRI Philippines. 
Flinn, J.C., M.D. Mercado. 1988. Economic perspectives of rice ratooning. In: Smith W.H., V. Kumble, E.P. Cervantes. (Eds.) Rice Ratooning, IRRI, Los Banos. Philippines. p. 17-29.

Gardner, F.P., R. Brent Pearce, Poger R. Michael. 1991. Fisiologi Tanaman Budidaya, Penterjemah Herawati Susilo. UI Press. Jakarta.

Islam, M.S., M. Hasannuzzaman, Rukonuzzaman. 2008. Ratoon rice response to different fertilizer doses in irrigated condition. Journal Agric Conspect Sci 73-4 (2008): 197-202.

Nair, S.A., C.A. Rosamma. 2002. Character association in ratoon crop of rice (Oryza sativa L.). Journal of Tropical Agriculture 40 (2): 1-3

Marschner 1995. Mineral Nutrition of Higher Plants. 2nd Ed. Academic Press Harcourt Brace and Company, London.

Santos, A.B., N.K. Fageria, A.S. Prabhu. 2003. Rice ratooning management practices for higher yields. Communication Soil Science. J Plant Anal 34: 881-918.

Vergara, B.S. 1995. A farmer's primer on growing rice. IRRI, Los Banos Philiphina. 